\title{
AN ELEMENTARY THREE-VARIABLE INEQUALITY WITH CONSTRAINTS FOR THE POWER FUNCTION OF THE NORMS ON SOME METRIC SPACES
}

\author{
ZHENG Li, TIE ZHANG AND CHANG-JUn Li
}

\begin{abstract}
A three-variable inequality with constraints for the $p$-power function of the norms on some metric spaces is established by an elementary technique. The new inequality performs sharper than the classical triangle inequality in the case $p=1$. The performance of the involved corollaries are compared with Jensen's inequality and Clarkson's inequality.
\end{abstract}

Mathematics subject classification (2010): 26D15, 39B62.

Keywords and phrases: Three-variable inequality, triangle inequality, Jensen's inequality, Clarkson's inequality, inequality for the power function of the norm.

\section{REFERENCES}

[1] P. Borwein, T. Erdélyi, Polynomials and Polynomial inequalities, Springer-Verlag New York Inc., New York, 1995.

[2] R. Bhatia, Matrix Analysis, Springer-Verlag New York Inc., New York, 1996.

[3] R. T. Rockafellar, Convex Analysis, Princeton University Press, Princeton, 1997.

[4] L. MaligRAndA, Some remarks on the triangle inequality for norms, Banach J. Math. Anal., 2, 2, 2008, 31-41.

[5] J. KuANG, Applied Inequalities (in Chinese), Shandong Science and Technology Press, 4th Edition, Jinan, 2010.

[6] W. Wang, Approaches to Prove Inequalities (in Chinese), Harbin Institute of Technology Press, Harbin, 2011.

[7] V. CIRTOAJE, The best lower bound for Jensen's inequality with three fixed ordered variables, Banach J. Math. Anal., 7, 1, 2013, 116-131.

[8] T. KochaneK, M. Lewicki, Characterisation of Lp-norms via Hölder's inequality, J. Math. Anal. Appl., 399, 1, 2013, 403-410.

[9] Y. NAKASUJI, Refinements of some inequalities related to Jensen's inequality, J. Math. Inequal., 8, 4, 2014, 685-692.

[10] S. G. WALKER, On a lower bound for the Jensen inequality, SIAM J. Math. Anal., 46, 5, 2014, 3151-3157.

[11] G. LU, New refinements of Jensen's inequality and entropy upper bounds, J. Math. Inequal., 12, 2, 2018, 403-421.

[12] J. Mıćı́́ НоT, Y. SEO, An interpolation of Jensen's inequality and its applications to mean inequalities, J. Math. Inequal., 12, 2, 2018, 303-313.

[13] R. A. Adams, J.J.F. Fournier, Sobolev Spaces, Elsevier Pte. Ltd., 2nd Edition, Singapore, 2009.

[14] D. XiA, Z. WU, S. YAN, W. SHU, Real Variable Function Theory and Functional Analysis(II) (in Chinese), Higher Education Press, 2nd Edition, Beijing, 2010.

[15] G. H. Golub, C. F. Van Loan, Matrix Computations, Post \& Telecom Press, 4th Edition, Beijing, 2014. 